\title{
Changes in properties of tropical ferruginous soils under long-term fertility management and continuous cultivation
}

\author{
G. C. Obiechefu ${ }^{1}$, K. U. Emerson ${ }^{2}$
}

${ }^{1}$ Department of Agricultural \& Bio-environmental Engineering, Imo State Polytechnic, Umuagwo-Ohaji, Nigeria ${ }^{2}$ Civil Engineering \& Geosciences, Newcastle University, United Kingdom

Received: 01 Jul 2021; Received in revised form: 25 Jul 2021; Accepted: 06 Aug 2021; Available online: 14 Aug 2021 (C2021 The Author(s). Published by Infogain Publication. This is an open access article under the CC BY license (https://creativecommons.org/licenses/by/4.0/).

\begin{abstract}
Soil fertility is an important resource to enhance crop productivity and meet global food demand. The present work investigated the impact of long-term fertility management and continuous cultivation on selected soil properties of ferruginous soils. 8 plots of the experimental research plot situated behind the Agricultural Extension Research and Liaison Services (AERLS) building in Samaru, Zaria, Nigeria,were subjected to different fertility treatment for over 50 years. These treatment were: control $(C)$; nitrogen $(N)$; nitrogen \& potassium (NK); nitrogen \& phosphorus (NP); nitrogen \& phosphorus \& potassium (NPK); dung \& potassium $(D P)$; dung \& nitrogen (DN); and dung \& nitrogen \& phosphorus (DNP). Using a completely randomized design (CRD) sampling technique, triplicate soil samples were collected from each fertility plot from the first $300 \mathrm{~mm}$ of the soil surface and analysed for selected properties. Results showed that the soils were majorly sandy loam. Sand component of the fertility plots was significantly $(P<0.05)$ higher compared to the Control, while silt was observed to have reduced in the experimental plots. Soil organic carbon (SOC) was significantly $(P<0.05)$ higher in the Control. Soils with dung as part of its fertilizer treatment showed slightly higher organic carbon content, with the DNP treatment having the highest value $(0.76 \%)$, while lowest OC $(0.36 \%)$ was recorded in the soils treated with inorganic fertilizer of NPK combinations. The OC content (0.35\%-0.78\%) recorded in soils of the various fertility plots was well below the $2 \%$ critical level required to guarantee soil structural stability. The $p H$ values of treated soils were from 5.1-6.1 and significantly $(P<0.05)$ higher in the Control. Bulk density was highest $\left(1620 \mathrm{~kg} / \mathrm{m}^{3}\right)$ in the Control, while the plot under DP showed the least value of $1520 \mathrm{~kg} / \mathrm{m}^{3}$. The different fertility treatments were observed to have reduced the plasticity of the soils from highly plastic recorded in Control to medium plastic observed in most of the other treatments. It is suggested that measures to enhance the soil OC be implemented as that will not only enhance the soil aggregate stability, but reduce the risk of soil erosion.
\end{abstract}

Keywords—Long-term, fertility management, soil quality, ferruginous, aggregate stability

\section{INTRODUCTION}

The need to sustain agricultural systems has become a concern of global dimension due to the rising decline in soil productivity. Soil quality and fertility are important resource to enhance crop productivity in order to meet the food required for the current and future population, particularly in the developing countries whose economy mainly depends on agriculture [1]-[4]. Soil quality means the capacity of the soil to deliver the intended functions for both biomass and yield production [5], [6].
When an agricultural land is under intense cultivation and use, there is the need to maintain soil fertility, soil sustainability and soil erosion control. Various methods have been adopted to achieve this. These include better land use management, continuous cultivation, crop rotation and fertility management programmes. Fertility management programmes refer to the various techniques adopted to enhance and ensure that essential plant nutrients are not depleted to undesirable levels. Fertility management is important to maintain crop yield and 
protect the land from the depletion of important soil nutrients.

In much of sub-Saharan Africa, the lack of organic soil amendments constitute one of the principal causes for declining soil fertility in intensifying farming systems. The challenge, therefore, remains to increase the availability of organic inputs and to develop recommendations for their combination with inorganic fertilizers [7].

Continuous and judicious application of manure has been shown to improve the physical and chemical properties of the soil, especially those that are coarse textured, or have low organic matter, thus reducing the potential for degradation of the quality of soil [7]. Interest in organic farming has increased following the determination that use of green manure and other organic matter can improve soil structure, improve nutrient exchange, and maintain soil health [8], [9].

The application of chemical fertilizers and organic manure to the soil has both positive and negative effects on plant growth and the soil properties. Though chemical fertilizers are relatively inexpensive, and have high nutrient contents which are rapidly absorbed by plants, applying them in excess can lead to a number of problems. Such problems may include loss of nutrient, contamination of surface water and groundwater, soil acidification, reductions in population of useful microbial communities, as well as increased sensitivity to harmful insects. On the other hand, use of organic manure is reported to have a number of deficiencies including slow decomposition and low nutrient in comparison to chemical fertilizers [10]. Despite the deficiencies in the use of organic fertilizer, it is reported to have multiple benefits due to the balanced supply of nutrients, increase in soil nutrient availability as a result of increased soil microbial activity, the decomposition of harmful elements, improvements in soil structure and root development, and increased soil water availability [10]. According to the authors, organic manure that generated from animal byproducts has been used to overcome environmental contamination and plant productivity reductions which are the results of prolonged application chemical fertilizers to the soil. The combined application of both chemical fertilizer and organic manure has shown diverse results in soil characteristic and plant yield.

Continuous cultivation and long-term fertility management programmes have direct bearing on soil structure and some other properties such as $\mathrm{pH}$, infiltration rates and erodibility; and if not properly managed, it may cause adverse effect on the soil. Understanding variability of soil fertility, its distribution and the causes of the observed variability are important to improve sustainable land use strategies [11]. This work was therefore designed to investigate changes in properties of Samaru soils in Zaria, Nigeria under long-term fertility management and continuous cultivation.

\section{MATERIALS AND METHODS}

\section{Location}

The experimental research plot for this study was situated behind the Agricultural Extension Research and Liaison Services (AERLS) building in Samaru, Zaria, Nigeria. Samaru ( $11^{\circ} 11^{\prime} \mathrm{N}, 07^{\circ} 38^{\prime} \mathrm{E}$, on altitude of $686 \mathrm{~m}$ above mean sea level) is situated in the Northern guinea savanna zone. Annual rainfall is about $1100 \mathrm{~mm}$ (May-September). The soils of the study area are classified as are ferruginous (a soil that is of or contains iron or iron rust) tropical soils formed from drift material, and are largely representative of the loess plain soil unit.

\section{Plot layout}

The plots behind the Agricultural Extension Research and Liaison Services building in Samaru were originally established to study and compare the effectiveness of inorganic fertilizers and dung (farmyard manure) in maintaining crop yield under continuous cultivation. It is a research project monitored by the Institute of Agricultural Research (IAR), Samaru. The soils were from the same parent body prior to commencement of the fertilizer treatment. A section of the research plots was thus selected for the purpose of this experiment. Eight (8) different blocks of the research plot were subjected to different fertilizer treatment. These treatment were: control (C); nitrogen $(\mathrm{N})$; nitrogen \& potassium $(\mathrm{NK})$; nitrogen \& phosphorus (NP), nitrogen \& phosphorus \& potassium (NPK). Other treatments were dung \& potassium (DP); dung \& nitrogen (DN); and dung \& nitrogen \& phosphorus (DNP). Source of nitrogen fertilizer used was ammonium sulphate; while single superphosphate and muriate of potash were used as source for $\mathrm{P}$ and $\mathrm{K}$ respectively. Fertilizer treatments were applied in two levels (Level 1 \& Level 2), and all plots were subjected to uniform continuous cultivation for a period of thirty-three (33) years. Treatment level 1 comprised supplying a specific amount of fertilizer for the first 22 years of the experiment, while treatment level 2 involved supplying another level of fertilizer for the remaining 13 years of the experiment. The application rate and total amount of fertilizer treatment received by respective plots during the period of the experiment is shown in Table 1. 
Table 1. Amount of fertilizer for Level 1 and Level 2

\begin{tabular}{|c|c|c|c|c|c|}
\hline \multirow{3}{*}{ Fertilizer type } & \multicolumn{4}{|c|}{ Treatment Level (kg/ha) } & \multirow{3}{*}{$\begin{array}{l}\text { Total amount of Fertilizer } \\
\text { received in } 33 \text { yrs. } \\
\text { (tonnes/ha) }= \\
\text { Total for } 22 \text { yrs. + Total } \\
\text { for } 13 \text { yrs. }\end{array}$} \\
\hline & \multicolumn{2}{|c|}{ Level 1} & \multicolumn{2}{|c|}{ Level 2} & \\
\hline & $\begin{array}{l}\text { Application } \\
\text { Per yr. }\end{array}$ & $\begin{array}{l}\text { Total for } \\
\text { in yrs. }\end{array}$ & $\begin{array}{l}\text { Application } \\
\text { Per yr. }\end{array}$ & $\begin{array}{l}\text { Total in } \\
13 \text { yrs. }\end{array}$ & \\
\hline Control & - & & - & & - \\
\hline $\mathbf{N}$ & 36 & 792 & 74.5 & 968.5 & 1.761 \\
\hline $\mathbf{P}$ & 14 & 308 & 48 & 624 & 0.932 \\
\hline $\mathbf{K}$ & 22.5 & 495 & 69 & 897 & 1.392 \\
\hline Dung (D) & 5000 & 110000 & 5000 & 65000 & 175 \\
\hline
\end{tabular}

Table 2. Total fertilizer treatment received by individual plots in 33 yrs.

\begin{tabular}{lccccc}
\hline \multirow{2}{*}{ Plot no } & Treatment combination & \multicolumn{3}{c}{ Total amount of Fertilizer received in 33 yrs. (tonnes/ha) } \\
\cline { 2 - 6 } & & Dung (D) & N & P & K \\
\cline { 2 - 6 } 1 & Control & - & - & - & - \\
2 & N & - & 1.761 & - & - \\
3 & NK & - & 1.761 & - & 1.392 \\
4 & NP & - & 1.761 & 0.932 & - \\
5 & NPK & - & 1.761 & 0.932 & 1.392 \\
6 & DP & 175 & - & 0.932 & - \\
7 & DN & 175 & 1.761 & - & - \\
8 & DNP & 175 & 1.761 & 0.932 & \\
\hline
\end{tabular}

\section{Soil sample collection}

This research adopted a completely randomized design (CRD) sampling technique. Triplicate soil samples were collected from each soil fertility treatment plot. Samples were collected from the first $300 \mathrm{~mm}$ of the soil surface using a soil auger. Samples were placed in black properly labeled polythene bags, and transported to the laboratory for analysis. Samples for bulk density were collected using a core sampler. Each soil sample was analyzed for $\mathrm{pH}$, organic carbon, bulk density, consistency limits, and particle size distribution (PSD).

\section{LABORATORY ANALYSIS}

Determination of selected soil chemical and physical properties

The bulk density of each soil sample was measured by determined by core sampler method [12], soil $\mathrm{pH}$ value was determined using a 1:2.5 soil to water paste and the glass electrode $\mathrm{pH}$ meter, organic carbon by Walkely and
Black's oxidation method as described by Jackson et al. [13].

Particle size analysis using sedimentation method

The hydrometer test was carried out to determine the percentage of sand, silt and clay in the soil samples from the various fertility plots. Percentage of sand, silt and clay were determine by hydrometer method [14] and the textural class was determined using the USDA textural triangle.

$\%$ sand $=\frac{\text { Sample weight }-40 \text { seconds reding }}{\text { Sample weight }}$

$\%$ clay $=\frac{8 \text { hour reading }}{\text { Sample weight }} \times 100$

$\%$ silt $=100 \%-(100 \%+$ clay $)$ 


\section{Determination of consistency limits}

The liquid limit was determined using the standard cup and grove method. This was carried out following the standard laboratory methods (ASTM standard test method D 4318). The plastic limit was determined by the method of rolling a $3 \mathrm{~mm}$ thread of the soil until the thread crumbles. The plasticity index was calculated as the difference between the value of the liquid and plastic limit of the soil.

\section{RESULTS AND DISCUSSION}

\section{Particle size distribution}

Table 3 shows the textural compositions, organic carbon, and $\mathrm{pH}$ of the soils under different fertility treatments. The results show that Samaru soils are basically Sandy loam with the exception of the Plot no 4 and 5 under NP and NPK treatments, respectively, which fall in the Loamy sand category.

Table 3. Effect of fertility treatment on selected soil properties

\begin{tabular}{cccccccc}
\hline Plot no. & $\begin{array}{c}\text { Soil } \\
\text { Treatment }\end{array}$ & Sand (\%) & Silt $(\%)$ & Clay $(\boldsymbol{\%})$ & Textural class & OC (\%) & pH \\
\hline 1 & Control & 59 & 37 & 4 & Sandy loam & 0.78 & 6.2 \\
2 & N & 54 & 40 & 6 & Sandy loam & 0.49 & 6.1 \\
3 & NK & 64 & 31 & 5 & Sandy loam & 0.35 & 5.4 \\
4 & NP & 77 & 20 & 3 & Loamy sand & 0.45 & 5.5 \\
5 & NPK & 75 & 21 & 4 & Loamy sand & 0.36 & 5.7 \\
6 & DP & 66 & 30 & 4 & Sandy loam & 0.70 & 5.8 \\
7 & DN & 72 & 24 & 4 & Sandy loam & 0.64 & 5.4 \\
8 & DNP & 66 & 30 & 4 & Sandy loam & 0.76 & 5.1 \\
LSD 5\% & & 1.413 & 1.322 & NS & & 0.030 & 0.166 \\
\hline
\end{tabular}

The sand content of the soils was significantly influenced by the fertility treatment. The sand content (54-77\%) dominated the textures, followed by silt (20-40\%) and clay contents (3-6\%) respectively. The sand fractions are mainly the fine sand fraction $(0.06 \mathrm{~mm}-0.2 \mathrm{~mm})$. These are very erodible fractions indicating that these soils are actually susceptible to erosion.

However, sand component of the various fertility treatment plots was observed to be significantly $(\mathrm{P}<0.05)$ higher compared to the Control, while silt was observed to have reduced in the experimental plots. No noticeable change in level was observed for clay fraction of the soil before and after the fertility treatment. Highest variation in sand and silt fractions relative to the Control plot was observed in the NP treatment plot with sand and silt percentages of $77 \%$ and $20 \%$ respectively, against $59 \%$ and $37 \%$ sand and silt percentages in the Control plot. The relative increase in the proportion of fines in the treatment plots could be the result of frequent mixing of the fertilizers and soil by machines used in the farm. According to Toy et al. [15], soils having more sand and silt components at the surface cap facilitates runoff, and are susceptible to water erosion. Compared to the Control plot, the results show that longterm fertility treatment did not cause any major change in the textural properties of the soils, though there were variations in the individual soil components.

\section{Soil organic carbon}

Soil OC was significantly $(\mathrm{P}<0.05)$ higher in the Control plot compared with the various treatments. Soils with dung as part of its main treatment treatment showed slightly higher organic carbon content, with the DNP treatment having the highest value $(0.76 \%)$, while lowest OC was recorded in the soils treated with inorganic fertilizer of NPK combinations. The result agrees with the findings of Islam et al. [16] who reported that the OC content of soils slightly decreased due to application of inorganic fertilizers while the results tended to increase in soils treated with organic fertilizer. Similarly, [17] reported that application of organic manure increased the OC content of the soil whereas a decreasing trend was detected with the application of chemical fertilizers. The soil OC recorded in the various plots $(0.35 \%-0.78 \%)$ was, however, below the $2 \%$ critical level suggested by [18] below which soil structural stability will not be guaranteed.

Soil OC is beneficial for long-term sustainability of the agro-ecosystem. It is reported that soil OC affects the soil physical, chemical and biological behaviour [19] and plays 
a significant role in maintaining soil quality andagricultural production [20]. It is also reported that SOC promotes aggregation, improve soil physical properties, and increase productivity and activity of soil organisms [21].

\section{Soil pH}

$\mathrm{pH}$ value was significantly $(\mathrm{P}<0.05)$ higher in the Control compared to the fertility treated soils. The $\mathrm{pH}$ values of treated soils were from $5.1-6.1$ indicating acidic nature, and with the DNP treated soil having the lowest value. A report by [22] showed that the soil $\mathrm{pH}$ decreased by the application of organic fertilizer. This is in agreement with the findings of Janzen [23] that application of nitrogen fertilizer significantly depressed soil $\mathrm{pH}$. The findings of this result is also in agreement with the report of Ge at al. [24] that long-term fertilization can decrease soil $\mathrm{pH}$ due to the continuous excessive application of $\mathrm{N}$ fertilizers. Likewise, [25] opined that addition of inorganic fertilizers increases soil acidity.

\section{Bulk density}

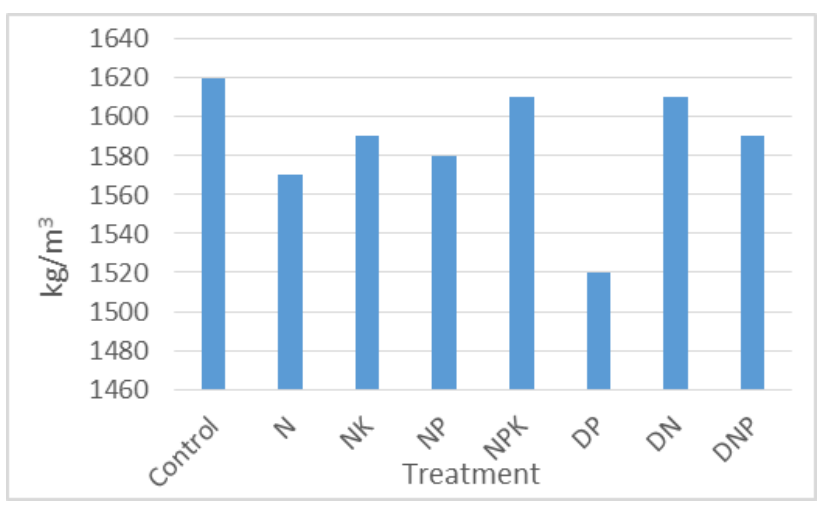

Fig. 1. Variation in bulk density for various soil treatments

Figure 1 showed that highest bulk density was highest in the Control, while the plots under fertility treatments showed slightly lower bulk densities. Among the fertility plots, highest bulk density was recorded in the NPK and DN plots respectively, while the lowest occurred in the $\mathrm{N}$ plot. Amoahet al. [7] reported that bulk densities of soils treated with cow dung and those with inorganic (NPK) fertilizer combined with cow dung were less than Control (with no fertilizer application). Reduction in bulk density of soil due to application of cattle manure in a long-term integrated nutrient management was also reported by [26]. Similarly, [27] reported decrease in bulk density of soils treated with inorganic fertilizer and those with inorganic fertilizer and farm yard manure as against Control with no fertilizer application under long-term fertility management. The authors however reported no significant difference in the bulk densities of the soils treated with inorganic fertilizer and those in combination with farm yard manure. According to Amoahet al. (2012), the decrease in bulk density could be attributed to manure effect, which improves the soil by reducing its density. The decrease in bulk density could also be the result of greater organic matter content of the soil and better aggregation [28].

\section{Soil consistency}

Table 4 shows the result of soil consistency with fertility treatment. Analysis of the soils showed that the Control was highly plastic, and the application of fertility treatment has reduced the plasticity. Thus, there was decrease in plasticity index of the soils under the various fertility treatments to medium plastic from highly plastic of the Control, with the exception of the plot under $\mathrm{N}$ treatment. Soils containing $\mathrm{N}$ and $\mathrm{P}$ are observed to have relatively lower plastic limits, while dung (D) appeared to be an improver of the plastic limit (i.e. increases plastic limit). The plasticity index is the difference between the plastic limit and the liquid limit and it indicates the range of moisture content over which soil have various shear strength values in increasing order from plastic limit, being highest at the plastic limit. Soils with low plastic limits had lower clay content, while soils with higher limits had higher clay contents. According to Ezeokonkwo [30], plastic soil become less plastic by the introduction of NPK fertilizer. The author reported that the plastic quality of the soil decreases as the percentage of fertilizer increases. The reason for was the bounding of fertilizer elements by the soil particles, a situation that could cause the soil containing NPK fertilizer to crumble easily. The findings of this study is also in agreement with the report of Paul and Abraham [31] that addition of fertilizer to soils affects the Atterberg's limits properties of the soil by reducing the liquid limit and the plastic limit of soils.

Table 4. Effect of fertility treatment on soil consistency

\begin{tabular}{cccccc}
\hline Plot no. & Soil treatment & Plastic limit $\%$ & $\begin{array}{c}\text { Liquid limit } \\
\%\end{array}$ & $\begin{array}{c}\text { Plasticity index } \\
\%\end{array}$ & Degree of plasticity* \\
\hline 1 & Control & 9.64 & 28.80 & 20.77 & High plastic \\
2 & $\mathrm{~N}$ & 9.23 & 30.00 & 20.27 & High plastic \\
3 & $\mathrm{NK}$ & 7.15 & 23.00 & 15.85 & Medium plastic
\end{tabular}




$\begin{array}{lccccc}4 & \text { NP } & 6.35 & 24.00 & 17.05 & \text { High plastic } \\ 5 & \text { NPK } & 7.64 & 23.00 & 15.36 & \text { Medium plastic } \\ 6 & \text { DP } & 10.43 & 24.00 & 13.57 & \text { Medium plastic } \\ 7 & \text { DN } & 8.48 & 22.60 & 14.12 & \text { Medium plastic } \\ 8 & \text { DNP } & 6.42 & 22.00 & 16.58 & \text { Medium plastic }\end{array}$

*Burmister [29]

\section{CONCLUSION}

Results of this study showed that properties of ferruginous soils are influenced by fertility treatment under long-term continuous cultivation. Inorganic fertilizer, when singly applied, or in combination with dung, affects the soil particle size, resulting in reduction of sand component and increase in silt. Clay component of the soils was not affected. Soil OC and $\mathrm{pH}$ were significantly $(\mathrm{P}<0.05)$ lower in the fertility plots compared to the Control. Longterm fertility treatment also resulted in lower soil bulk density and plasticity from high to medium plasticity. Bulk density was highest $(1620 \mathrm{~kg} / \mathrm{m} 3)$ in the Control, while the plot under DP showed the least value of $1520 \mathrm{~kg} / \mathrm{m}^{3}$. Measures to enhance the soil OC are thus recommended as that will not only enhance the soil aggregate stability, but reduce the risk of soil erosion.

\section{REFERENCES}

[1] Arshad MA, Martin S. 2002. Identifying critical limits for soil quality indicators in agro-ecosystems. Agric Ecosyst Environ. 88:153-160.

[2] Yildirim, E. and Guvenc, I (2005). Intercropping based on cauliflower: more productive, profitable and highly sustainable.Eur J Agron. 22: 11-18.

[3] Sharma, K. L., Mandal, B. and Venkateswarlu, B. (2012). Soil quality and productivity improvement under rainfedconditions - Indian perspectives. In: Abrol V, Sharma P, editors. Resource management for sustainable agriculture. InTech, India, 2012; p. 203-238.

[4] Negasa, T., Ketema, H., Legesse, A., Sisay, M. and Temesgen, H. (2017). Variation in soil properties under different land use types managed by smallholder farmers along the toposequence in Southern Ethiopia. Geoderma.290: 40-50.

[5] Mairura, F. S., Mugendi, D. N., Mwanje, J. I., Ramisch, J. J., Mbugua, P. K. and Chianu, J. N. (2008). Scientific evaluation of smallholder land use knowledge in Central Kenya. Land Degrad. Dev., 19: 77-90.

[6] Tesfahunegn, G. B. (2016). Soil quality indicators response to land use and soil management systems in northern Ethiopia's catchment. Land Degrad. Dev. 27: 438-448.

[7] Amoah, A. A., MasateruSenge, Shuichi Miyagawa andKengo Itou (2012). Effects of Soil
Management on Growth, Yield, and Water- Use Efficiency of Maize (Zea mays L.) and Selected Soil Properties. Communications in Soil Science and Plant Analysis, 43:6, 924-935.

[8] Ayoub, A. T. (1999). Fertilizer and environment. Nutrient Cycling in Agroecosystems 55:117-121.

[9] Becker, M., J. K. Ladha, and M. Ali. 1995. Green manure technology: Potential usage, limitations: A case study for lowland rice. Plant and Soil 174:181-194.

[10] Han, S. H., An, J. Y., Hwang, J. H., Kim, S. B. \& Park, B. B. (2016). The effects of organic manure and chemical fertilizer on the growth and nutrient concentrations of yellow poplar (Liriodendron tulipifera Lin.) in a nursery system. Forest Science and Technology Vol. 12, No. 3, September 2016, 137-143.

[11] Jing-wei J., Hui-chun Y., Yue-fei X., Chong-yang S. and Yuan-fang H. (2011). Spatial and temporal patterns of soil fertility quality and analysis of related factors in urban-rural transition zone of Beijing, African J Biotechn, 0(53), 10948-10956.

[12] Z. Karim, S. M. Rahman, M. I. Ali, and A. J. M. S. Karim, Soil Bulk Density. A Manual for Determination of Soil Physical Parameters, Soils and Irrigation Division, BARC, 1988.

[13] M. L. Jackson, Soil Chemical Analysis, Constable and Co. Ltd. Prentice Hall of India Pvt. Ltd, New Delhi, India, 1973.

[14] [C. A. Black, Method of Soil Analysis Part-I and II, American Society of Agronomy, Madison,Wis, USA, 1965.

[15] Toy, J. T., George, R. F. and Kenneth, G.R. (2002). Soil erosion. New York (NY), Wiley.

[16] Islam, M. R., S. Sikder, M. M. Bahadur and M. H. R. Hafiz (2012). Effect of Different Fertilizer Management on Soil Properties and Yield of Fine Rice Cultivar. J. Environ. Sci. \& Natural Resources, 5(1): 239-242.

[17] Azim, S. M. A., Rahman, M. M., Islam M. R. and Hoque M. A. (1999). Effect of sulphur, zinc and boron supplied from manures and fertilizers on BRRI Dhan 29. M.S. Thesis. Dept. Soil Sci. (Jan- June, Semester), BAU, Mymensingh.

[18] Parwada, C. \&Tol, J. V. (2016). Soil properties influencing erodibility of soils in the Ntabelanga area, Eastern Cape Province, South Africa, Acta Agriculturae Scandinavica, Section B - Soil \& Plant Science, DOI:10.1080/09064710.2016.1220614 
[19] Craswell, E.T. and R.D.B. Lefroy, 2001. The role and function of organic matter in tropical soils. Nutrient Cycling Agroecosyst., 61: 7-18.

[20] Zhang, S., X. Yang, M. Wiss, H. Grip and L. Lovdahl, (2006). Changes in physical properties of a loess soil in China following two long-term fertilization regimes. Geoderma, 136: 579-587.

[21] Paradelo, R., Virto, I. and Chenu, C. (2015). Net effect of liming on soil organic carbon stocks: a review. Agriculture, Ecosystems and Environment 202:98-107.

[22] Paradelo, R., Virto, I. and Chenu, C. (2015). Net effect of liming on soil organic carbon stocks: a review. Agriculture, Ecosystems and Environment 202:98-107.

[23] Janzen, H. H. (1987). Effect of fertilizer on soil productivity in long-term spring wheat rotations. Can. J. Soil Sci. 67:165-174.

[24] Ge, S., Zhanling Zhu and Yuanmao Jiang (2018). Longterm impact of fertilization on soil $\mathrm{pH}$ and fertility in an apple production system. Journal of Soil Science and Plant Nutrition, 18 (1): 282-293.

[25] Devaney E. (2010). Environmental Effects of Chemical Fertilizers. $\quad$ http://www.ehow.com/facts_envt-effects fert.html.

[26] Schjønning, P., B. T. Christensen, and B. Carstensen (1994). Physical and chemical properties of sandy loam receiving animal manure, mineral fertilizer or no fertilizer for 90 years. European Journal of Soil Science 45:257268.

[27] Brar, B. S., Jagdeep Singh, Gurbir Singh and Gurpreet Kaur (2015). Effects of Long Term Application of Inorganic and Organic Fertilizers on Soil Organic Carbon and Physical Properties in Maize-Wheat Rotation. Agronomy, 5: 220238.

[28] Tiarks, A. E., A. P. Mazurak, and L. Chesinin(1974). Physical and chemical properties of soil associated with heavy application of manure from cattle feedlots. Soil Science Society of America Proceedings 38:826-830.

[29] Burmister, D. M. (1949). Monograph Title: Proceedings of the Twenty-Ninth Annual Meeting of the Highway Research Board Held at Washington, D.C. December 1316, 1949.

[30] Ezeokonkwo, J. C. (2011). Engineering Properties of NPK Fertilizer Modified Soil. Journal of Emerging Trends in Engineering and Applied Sciences (JETEAS) 2(6): 962-966.

[31] Paul, V. C. and Abraham, J. K. (2011). Effect of Fertilizers on Soil Strength. International Research Journal of Engineering and Technology (IRJET), 4(5) 2307-2311. 